\title{
Total Assessment-Reassessment \& Evaluation Using Biokinesiologic (TAREK) Approach for Resolving Complicated Cases
}

\author{
Tarek M El Gohary ${ }^{1^{*}}$ and Talal Aljeraisi ${ }^{2}$ \\ ${ }^{1}$ Department of Biomechanics, Taibah University, Saudi Arabia \\ ${ }^{2}$ Department of Head\& Neck Surgery, Taibah University, Saudi Arabia
}

Submission: May 14, 2018; Published: May 30, 2018

*Corresponding author: Tarek M El Gohary, Department of Biomechanics, College of medical rehabilitation sciences, Taibah University, PO Box 344, Saudi Arabia, Email: dr.elgoharyt@yahoo.com.

\begin{abstract}
The longstanding of stubborn symptoms and the poor response to physical therapy constitute a real challenge to physical therapists and rehabilitation professionals. The purpose of the study was to provide clinicians with a new approach for evaluating complicated cases. The study subject was a 59 years old house wife who had long history of sufferance since she had a major car accident 22 years ago. The patient was evaluated by the expert in the field in collaboration with a medical doctor aiming to help the patient to overcome the sufferance. The new evaluation approach was satisfactory in addressing patient's needs and in resolving many of unexplained symptoms. It has been concluded that Total Assessment- Reassessment \& Evaluation using bioKinesiologic (TAREK) approach is feasible but robust in providing clinicians with a systematic way for resolving longstanding complicated sufferance.
\end{abstract}

Keywords: Clinical reasoning; Clinical judgment; TAREK approach; Case report

\section{Introduction}

Motor vehicle accidents (MVA) constitute one of the main leading causes of morbidity in Kingdom of Saudi Arabia [1]. MVA is not only resulting in property damage and mortality but also morbidity and sufferance that could be for the rest of life especially among young people [2]. The complexity of the longstanding medical and physical complaints left clinicians with absence of specific evidence- based evaluation strategy to address patients' sufferance. The gap in the body of knowledge has urged distinguished clinicians to introduce some evaluation methods. Recently, El Gohary et al. [3] have published Total Assessment- Reassessment \& Evaluation using BioKinesiologic (TAREK) approach to help clinicians in resolving complex manifestations using systematic way of clinical reasoning and clinical judgment under umbrella of critical thinking $[4,5]$. The poor response to regular physical therapy intervention and the undetermined source of complaints have prompted the interventionist to refer the patient for evaluation using TAREK approach (Figure 1). The evaluation was conducted by the Dr. El Gohary [3], the expert in the field who had originally formulated TAREK approach in addition to have assistance from a medical doctor specialized in Otorhinolaryngology to have a detailed assessment of cranial nerves involvement. It is hypothesized that TAREK approach will help clinicians to pinpoint the sources of disorders to unlock the haziness of complicated cases.

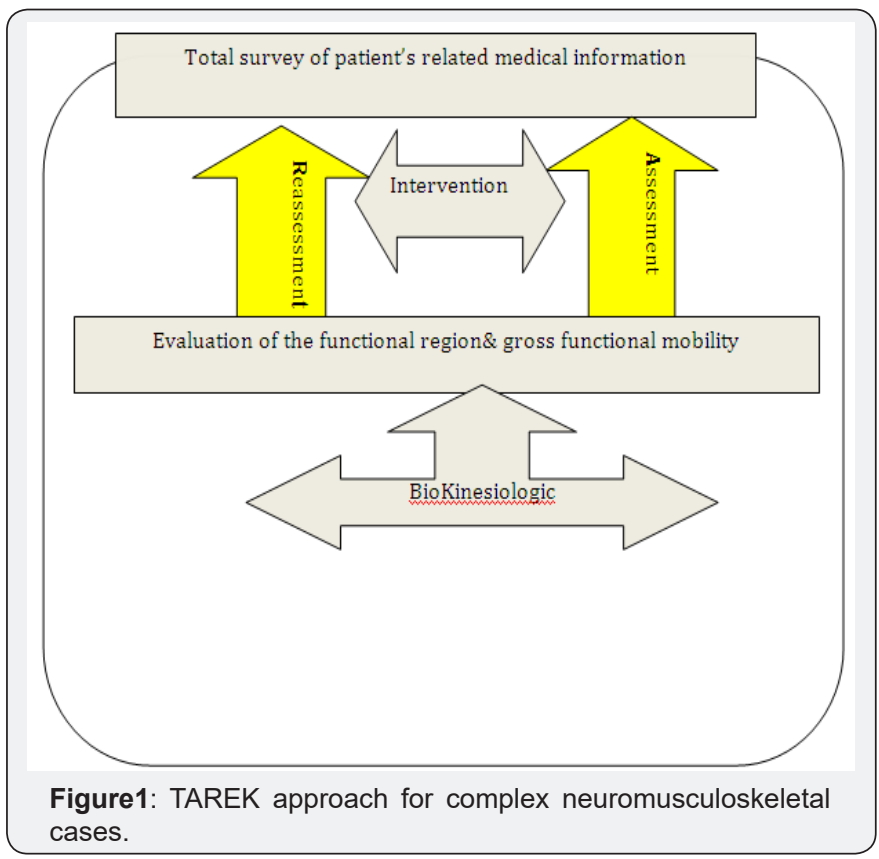




\section{Case Report}

The study subject was a 59 years old right hand dominant house wife, mother of three, reported to physical therapy outpatient clinic for evaluation. Patient was evaluated by the expert who is a board certified orthopedic physical therapy consultant in addition to being certified by McKenzie institute of North America to provide mechanical diagnoses and therapy $[6,7]$. The consultant had the evaluation in collaboration with a medical doctor who is specialized in otorhinolaryngology. Patient stated that she had major car accident 22 years ago. Patient was not seat belted and lost her consciousness at the time of the accident. Patient stated that she had major and severe head trauma that required head surgery. She also had several bone fractures. She does not have the records except little records that indicated scapula fracture, and right shoulder dislocation at that time. Patient does not have any radiologic reports but she indicated that she was told that she should not subject to any imaging on her head and brain. Patient indicated that her hands numbness and tingling, and shoulders pain are her chief complaints. Pain is $2 / 10$ at the time of evaluation which goes up to $8 / 10$ at worst and goes down to $1 / 10$ at best. Patient also indicated that her numbness and tingling started 10 years ago and has been present since. Patient added that she feels that her case is worsening. Patient indicated that her shoulder pain is the kind of dull ache which shoots down arms with right more than left arm. Patient indicated that elevating her arm up increases pain, numbness and tingling while resting the arm on support eases symptoms. Patient reported that the pain and the tingling in her hands and fingers wakes her up from sleep and limit her during activity of daily living like cooking, cleaning and knitting. Patient added that she does like to take medications and tends to rely on natural herb. Patient becomes very cautious when change her body position with rotatory movement since she experiences vertigo and loses her balance. Patient has limited end range of all neck movements especially the neck extension during looking at the ceiling. All shoulder movements are within functional limits for orthogonal and composite movements but of poor quality especially for putting hands behind lower back. Patient also mentioned that she stumbled couple of month ago and since then she is suffering from painful left big toe at the metatarsophalangeal joint. No significant social or family history, comorbidities, or significant lab findings. Patient has limited and painful passive accessory antero-posterior humeral head gliding. Trunk forward bending test is completely normal. Patient was noticed to sit slouched with forward head-neck posture. Manual muscle testing of upper and lower extremities is within functional limits. Patient has significant difficulties to balance on one leg, with the left side more than right side, especially with eyes closed. Observational gait analysis showed no apparent deficits. Patient has +ve neck quadrant which aggravates when applying compression on the neck at that position. Patient has paresthesia at all fingers. Crank test is questionable when applied to right shoulder. O'Brien test is +ve on the right shoulder. No imminent red or yellow flags were detected.

\section{Results}

Using TAREK approach for evaluation has helped clinicians to extract pertinent information from the patients while performing physical and clinical assessments. It has also helped clinicians to adopt a systematic approach that facilitated the analytical skills necessary to diagnose problems and devise viable solutions. Clinicians came up with the following workable diagnoses: A status of post traumatic neck and left shoulder derangement; post traumatic vertigo; painful end range stiffness of all neck movements particularly neck extension; subtle right shoulder pathomechanics; and bilateral hands and fingers numbness, tingling and burning pain.

\section{Discussion}

TAREK approach has shown satisfactory evidence of addressing and resolving some of the sufferance in the presented chronic and complicated post traumatic neuromusculoskeletal case. The expert has involved the patient as active partner in the evaluation process in addition to have a medical doctor who is specialized in otorhinolaryngology to have a comprehensive evaluation for all aspects of sufferance [8,9]. Having the patient as active partner will help the therapist to evaluate the value of rehabilitation to every patient's particular sufferance [8]. TAREK approach allowed the within session- and the consecutive sessions- reassessment after short or extended sessions of intervention respectively. TAREK approach enabled clinicians to use a holistic approach to assess axial and appendicular skeleton, evaluating every functional region and evaluating the overall functional performance of the patient [10]. Patient was instructed to come for follow up consultation and to modify plane of care as needed. In conclusion, clinicians were successful when used TAREK approach in evaluating the complicated symptoms and determining the pathomechanical aspects of sufferance.

\section{Acknowledgment}

The authors would like to thank all clinicians at outpatient clinic of medical rehabilitation hospital, Al-Madina Al-Munawara, KSA.

\section{References}

1. Mansuri FA, Al Zalabani AH, Zalat MM, Qabshawi RI (2015) Road safety and road traffic accidents in Saudi Arabia. A systematic review of existing evidence. Saudi Med J 36(4): 418-424.

2. Ghaffar UB, Ahmed SM (2015) A review of road traffic accidents in Saudi Arabia: the neglected epidemic. Indian J Forensic Community Med 2: 242-246.

3. El gohary TM, Emara HA, Awadallah MF (2018) Total assessmentreassessment \& evaluation using bioKinesiologic (TAREK) approach: case presentation for theoretical formulation. J Phys Ther Sci 30(3): 439- 442.

4. El gohary TM, Abdelkader SM (2018) Deconditioning and functionalphysical decline: clinical reasoning and clinical judgment using TAREK approach. Case study 7: 63-68. 
5. (2018) Ten critical thinking and clinical reasoning -pearson higher.

6. (2018) Orthopedic specialist certification candidate guide- ABPTS.

7. (2018) The Mckenzie institute international.

8. Kyte DG, Calvert M, Van der Wees PJ, Ten Hove R, Tolan S, et al. (2015) An introduction to patient-reported outcome measures (PROMs) in physiotherapy. Physiotherapy 101(2): 119-125.
9. Alami S, Palazzo C, Poiraudeau S (2015) Checklists to manage pain induced by exercise and mobilization (PIEM) during physical therapy programs: PIEM checklists for practitioners and physiotherapists. Annals of physical and rehabilitation medicine. 58(2): 66-73.

10. El gohary TM (2018) Post traumatic cervical anterolithesis: Comprehensive evaluation and expert opinion based on clinical reasoning and clinical judgment skills. Journal of Taibah University Medical Sciences.

\section{Your next submission with Juniper Publishers} will reach you the below assets

- Quality Editorial service

- Swift Peer Review

- Reprints availability

- E-prints Service

- Manuscript Podcast for convenient understanding

- Global attainment for your research

- Manuscript accessibility in different formats

( Pdf, E-pub, Full Text, Audio)

- Unceasing customer service

ack the below URL for one-step submission

https://juniperpublishers.com/online-submission.php 